\title{
EVALUACIÓN DE ESTRATEGIAS DE CONTROL DE MALE- ZAS EN EL CULTIVO DE LILIUM PARA FLOR CORTADA. ENSAYO II: HERBICIDAS DE POSTEMERGENCIA*
}

\section{EVALUATION OF WEED CONTROL STRATEGIES IN A LI- LIUM CROP FOR CUT FLOWER PRODUCTION. EXPERIMENT II : POSTEMERGENCE HERBICIDES}

\author{
Espinoza, N., Chahin A., y Valenzuela B. B. \\ INIA Carillanca, Km 10 camino Cajón Vilcún, Casilla 58-D. E-mail: gchahin@inia.cl \\ INTRODUCCIÓN \\ En condiciones de campo o ambientales natu- \\ rales, el control de las malezas se hace princi- \\ palmente a través rotaciones de cultivo, prepa- \\ ración del suelo, uso de cultivadores manuales y \\ posible para lograr reducir al mínimo la interfe- \\ rencia de las invasoras (Fuentes, 1999). El obje- \\ tivo del presente trabajo fue evaluar la eficacia \\ sobre las malezas y selectividad en el cultivo \\ del lilium de diversos herbicidas aplicados de \\ posemergencia, en la IX Región.
} mecanizados, y en algunos casos con el empleo de plásticos (mulch) y mediante solarizaciones (Fuentes, 1999). Al control químico, aunque se le reconoce una mayor eficiencia respecto a los demás métodos, está relativamente poco desarrollado en plantas bulbosas ornamentales, básicamente por la reducida disponibilidad de herbicidas con selectividad comprobada en cada una de las especies. La principal razón es que estas especies son cultivadas en áreas relativamente pequeñas y la industria de agroquímicos desarrolla sus productos principalmente para uso en cultivos extensivos (Fuentes, 1999). En el extranjero los herbicidas son comúnmente usados en viveros ornamentales, porque son más efectivos y de menor costo que el control manual (Weatherspoon, citado por Salihu, 1997), sin embargo, la tolerancia de los cultivos a los herbicidas varía según la especie y cultivar (Neal y Senesac; Jacobsen y Walls, citados por Salihu, 1997). La mayoría de los herbicidas usados en cultivos ornamentales han sido inicialmente desarrollados para su uso en otro cultivo de gran extensión y posteriormente, se extiende su empleo a especies como las bulbosas ornamentales, careciendo muchas veces de un buen margen de selectividad, por lo que la eficacia de control tiende a ser variable. Por tanto, ante las restricciones de alternativas de control de malezas, las prácticas de manejo deben ser lo más integradas

\section{MATERIALES Y MÉTODOS}

Bajo condiciones ambientales naturales en el Centro Regional de Investigación INIA Carillanca, comuna de Vilcún, IX Región, $38^{\circ} 41^{\prime}$ Lat. S. y $72^{\circ} 25^{\prime}$ Long. W el 20 de septiembre del 2000, se plantó bajo malla de sombra bulbos de lilium asiático de la variedad Gran Sasso, de calibre 10/12. a una densidad de 42 bulbos por $\mathrm{m}^{2}$. La fertilización se hizo de acuerdo al análisis de suelo y el manejo sanitario según calendario de aplicaciones preventivas contra botrytis, trips y pulgones, los principales problemas del cultivo en la zona (Chahin, 1999). Se definieron diez tratamientos: cuatro herbicidas (Simazina, Metamitron, Asulam y Bentazon), aplicados en dos dosis cada uno y dos testigos sin herbicida (enmalezado y limpio a mano). Todos los herbicidas se aplicaron con un aspersor manual que contenía una barra con cuatro boquillas Tee Jet 8002 , utilizando un volumen de agua fue $200 \mathrm{~L}$ ha $^{-1}$. Esta se realizó a los 32 días posplantación. Los tratamientos se ordenaron en el terreno según un diseño de bloques completos al azar con tres repeticiones. Para determinar la eficacia de control de malezas de los tratamientos, las estimaciones visuales se realizaron a $\operatorname{los} 24$ y 41 días después de la aplicación, la determinación de la densidad del total de malezas $\left(\mathrm{N}^{\circ} \mathrm{m}^{-2}\right)$ en 
Cuadro 1. Control visual del total de malezas transcurridos diferentes períodos después de la aplicación de los herbicidas en post-emergencia.

Table 1. Visual control of total weed covering at different periods of time, after post-emergence herbicides application.

\begin{tabular}{lccc}
\hline & Tratamiento & Cosis $\left(\mathbf{K g}\right.$ i.a.ha $\left.{ }^{-1}\right)$ & \multicolumn{2}{c}{ Control visual $(\%)^{\mathbf{1}}$} \\
& 24 DDA & 41 DDA \\
\hline Simazina (1) & 1,5 & 55 & 42 \\
Simazina (2) & 2,5 & 76 & 75 \\
Metamitron (3) & 2,1 & 82 & 64 \\
Metamitron (4) & 4,2 & 84 & 73 \\
Asulam (5) & 0,8 & 60 & 50 \\
Asulam (6) & 1,6 & 62 & 58 \\
Bentazon (7) & 1,2 & 75 & 45 \\
Bentazon (8) & 1,92 & 85 & 72 \\
Testigo sin herbicida (enmalezado) (9) & -- & 0 & 0 \\
Testigo sin herbicida (limpio a mano)(10) & - & 100 & 100 \\
\hline
\end{tabular}

'Escala $0-100 \%$, en que $0 \%$ indica ningún control y $100 \%$ indica control total. DDA indica días desde la aplicación de los herbicidas, i.a indica Ingrediente Activo.

Los herbicidas metamitron y bentazon aplicados en postemergencia en las dosis de 4,2 y 1,92 $\mathrm{Kg}$ i.a./ha respectivamente, tuvieron un control más eficaz de las malezas de hoja ancha en el cultivo de lilium var. Gran Sasso. También se destacaron las dosis de 2,1 y $1,2 \mathrm{Kg}$ i.a./ha respectivamente. Los herbicidas de postemergencia no afectaron las variables de producción como altura de varas y número de bolones florales por vara

un área de $0,25 \mathrm{~m}^{2}$, y por especie a los 47 días después de la aplicación, y la determinación del peso seco de la parte aérea $\left(\mathrm{g} \mathrm{m}^{-2}\right)$ de las malezas a los 90 días después de la aplicación. En el cultivo se evaluó largo de la vara floral y número de botones por vara.

\section{RESULTADOS}

Transcurridos 24 días desde la aplicación de los herbicidas, los tratamientos más eficaces para controlar las malezas correspondieron a simazina en dosis alta, metamitron en ambas dosis y bentazon en ambas dosis (Cuadro 1). Posteriormente, a los 41 días desde la aplicación hubo un decrecimiento en el control con todos los herbicidas, especialmente con bentazon y metamitron. Sin embargo, continuó siendo relativamente alto con simazina y metamitron en la dosis alta. Las especies más importantes en relación a densidad correspondieron a las poligonáceas porotillo, vinagrillo, duraznillo y sanguinaria; a las compuestas mil en rama, hierba del chancho y diente de león; y en el grupo de otras malezas a pasto pinito, viola y trébol blanco.

\section{BIBLIOGRAFÍA}

CHAHÍN, M. 1999. Producción de Tulipán, Lilium y Gladiolos. Serie Inia Carillanca. Chile. 65 p.

FUENTES, R. 1999. Control de malezas en plantas bulbosas. Seemann, P; Andrade, N. (eds.). Cultivo y Manejo de Plantas Bulbosas Ornamentales. Universidad Austral de Chile, Facultad de Ciencias Agrarias, pp: 179-193.

SALIHU, S. 1997. Basis for selectivity of isoxaben in Ajuga (Ajuga reptans), Wintercreeper (Euonymus fortunei), and Dwarf burning bush (Euonymus alatus 'Compacta'). Tesis Doctor of Phylosophy in Weed Science. Virginia Polytechnic Institute and State University.

Bllacksburg, Virginia. Estados Unidos. http://scholar. lib.vt.edu/theses/available/etd-1243112249741411

\footnotetext{
* Financiado por el programa FNDR Centro de generación, capacitación y transferencia de tecnología en producción de flores para la exportación, IX región. Código BIP 20134475-0, ejecutado por INIA Carillanca.
} 